\title{
Usage and Perceptions of Mobile Devices and Applications among HE Instructors
}

\author{
Ahmed Al-Hunaiyyan and Rana Al-Hajri
}

\begin{abstract}
Successful implementation of Information and Communication Technologies (ICT) requires an understanding of the role of technology on Higher Education (HE) institutions and on current teaching and learning practices. Recent innovations in mobile technology and social networking applications have made mobile devices more dynamic and pervasive promising more educational potential. Educators in HE Institutions must embrace and capitalize on the use of this technology to focus on integrated student services, and to enhance knowledge sharing activities in and off campus. This study investigated instructors' usage and perceptions of mobile devices, functions, native capabilities, and applications. A sample of 48 instructors was involved in this investigation at the college of Business Studies (CBS) in Kuwait. The aim of this study is to understand instructors' usage and perceptions of mobile capabilities and functions. The finding indicated instructors' frequent use of most of mobile functions and demonstrated that instructors would like to use mobile in their teaching practices. This will guide designers to identify critical success factors and help developers to effectively utilize mobile capabilities, functions, and applications in new learning strategies.
\end{abstract}

Index Terms-Higher education (HE), mobile functions, mobile perceptions.

\section{INTRODUCTION}

The expanding capabilities of mobile devices and applications are increasingly becoming prevalent. Mobile devices and applications have a great role in enhancing knowledge sharing activities among academicians and help in creating new ways to connect with their campuses, course materials, students' records, and their colleagues [1]. The ubiquity of mobile devices and mobile unique capabilities which includes connectivity, portability, GPS, and cameras have great potential to enrich the teaching experience [2]. Plenty of mobile features such as GPS, file storage, cameras, video recorder and browsing, made academicians see mobile phone technologies important tool when it comes to managing the teaching tasks [3]. As the population of campuses expands, so does the improvement of mobile technologies, Higher Education Institutions utilize mobile technologies with interesting features like camera, video, GPS, memory, MP3 player, by allowing studying and collaboration anytime anywhere [4], [5].

The rapid development and growth of mobile technology has motivated developers to reshape industries and businesses [6], and has led to the introduction and use of

Manuscript received February 12, 2018, revised April 20, 2018.

The authors are with Computer Science Department, Public Authority of Applied, Education and Training, Kuwait (e-mail: aa.alhunaiyyan@paaet.edu.kw, Rana_alhajri@yahoo.com). mobile systems in education [7]. Kuwait has experienced strong growth in mobile penetration [8]. The high mobile phone availability among people in Kuwait is important factor that motivated the researchers to conduct this study. This Study explores the use and perceptions of mobile native functions, capabilities, and applications among instructors, at the College of Business Studies (CBS), in Kuwait, with over 500 instructors at the college and more than 5 thousand students. A sample of 48 instructors was involved in this investigation at the college of Business Studies (CBS), a HE institution in Kuwait. The aim of this study is to understand instructors' habits of the use of mobile capabilities and functions.

The rest of this article is organized as follows: Section 2 introduces the literature review, and section 3 explains the methodology used for this study. Section 4 presents results and findings, while section 5 concludes the study.

\section{LITERATURE REVIEW}

There are many theoretical studies concerning mobile services, functions, and applications, a significant number of research investigated users' preferences and usage [3], [5]. The vast majority of these studies indicated a growing importance of mobile devices in everyday life and pointed at the increased usage of new capabilities and functions [9]-[11]. However, there is a lack of studies that focus on examining instructors' perceptions of m-learning, particularly in the context of Kuwait higher education (HE) institutions [12].

According to studies performed by [4], mobile technologies could be used for many applications for academicians and students both inside and outside Higher Education Institutions (HE). The results of a studies conducted by [13], [14] mobile technologies allowed users to conduct 9 activities in HE institutions such as: sending photos/videos to colleagues, using mobile as audio player, accessing information or services on the web, making video calls, taking photos, or recording movies, sending, or receiving email, using the mobile as personal organizer, sending or receiving SMS, and calling colleagues or others. In addition, [5] explored student and instructor perceptions of personal mobile device usage for appropriate practices at a Brazilian higher education institution. The study also investigated and documented significant differences in perceptions, and found relationships between perceptions and demographic data [5].

Moreover, the study of [15] reports faculty perceptions regarding students' use of personal technology in the classroom. The findings indicated that some faculties ban it, some ignore it, and some use it to enhance the classroom 
experience. Similarly, [16] conducted a study to examined teacher educators' attitudes towards the use of mobile technology in classes, and their reactions to its use. The findings show that instructors perceive the benefits of using mobile technology in their classes as outweighing the disadvantages. Another study conducted by [17] investigated instructors' perceptions and experience of using mobile phones in teaching and learning in the United Arab Emirates. Their Main findings suggest that none of the instructors had formally integrated the mobile devices into their teaching, though they were aware of its educational opportunities.

\section{Methodology}

\section{A. Purpose of the Study}

The purpose of this study is to seek instructors' usage and perceptions of mobile devices, functions, native capabilities, and applications.

TABLE I: INSTRUCTORS' USE OF MOBILE FUNCTIONS AND APPLICATIONS

\begin{tabular}{|c|c|c|c|c|c|c|c|c|}
\hline & Mobile Native Function & pplications & Yes & No & I don't Know it & Mean & SD & Sig. \\
\hline \multirow{2}{*}{1} & \multirow{2}{*}{ Call } & Male & $38 \%$ & $0 \%$ & $0 \%$ & 3.00 & .000 & \multirow{2}{*}{.000} \\
\hline & & Female & $44 \%$ & $6 \%$ & $12 \%$ & 2.50 & .820 & \\
\hline \multirow{2}{*}{2} & \multirow{2}{*}{ SMS/MMS } & Male & $31 \%$ & $6 \%$ & $0 \%$ & 2.83 & .383 & \multirow{2}{*}{.000} \\
\hline & & Female & $38 \%$ & $25 \%$ & $0 \%$ & 2.60 & .498 & \\
\hline \multirow{2}{*}{3} & \multirow{2}{*}{ WhatsApp } & Male & $32 \%$ & $0 \%$ & $6 \%$ & 2.67 & .767 & \multirow{2}{*}{.586} \\
\hline & & Female & $50 \%$ & $6 \%$ & $6 \%$ & 2.70 & .651 & \\
\hline \multirow{2}{*}{4} & \multirow{2}{*}{ Calendar } & Male & $31 \%$ & $6 \%$ & $0 \%$ & 2.83 & .383 & \multirow{2}{*}{.006} \\
\hline & & Female & $44 \%$ & $13 \%$ & $6 \%$ & 2.60 & .675 & \\
\hline \multirow{2}{*}{5} & \multirow{2}{*}{ Camera } & Male & $38 \%$ & $0 \%$ & $0 \%$ & 3.00 & .000 & \multirow{2}{*}{.000} \\
\hline & & Female & $50 \%$ & $6 \%$ & $6 \%$ & 2.70 & .651 & \\
\hline \multirow{2}{*}{6} & \multirow{2}{*}{ Alarm/ Clock } & Male & $38 \%$ & $0 \%$ & $0 \%$ & 3.00 & .000 & \multirow{2}{*}{.003} \\
\hline & & Female & $56 \%$ & $0 \%$ & $6 \%$ & 2.80 & .610 & \\
\hline \multirow{2}{*}{7} & \multirow{2}{*}{ Listening to Sound } & Male & $25 \%$ & $12 \%$ & $0 \%$ & 2.67 & .485 & \multirow{2}{*}{.647} \\
\hline & & Female & $44 \%$ & $19 \%$ & $0 \%$ & 2.70 & .466 & \\
\hline \multirow{2}{*}{8} & \multirow{2}{*}{ Browsing the Web } & Male & $38 \%$ & $0 \%$ & $0 \%$ & 3.00 & .000 & \multirow{2}{*}{.000} \\
\hline & & Female & $44 \%$ & $18 \%$ & $0 \%$ & 2.70 & .466 & \\
\hline \multirow{2}{*}{9} & \multirow{2}{*}{ Games } & Male & $13 \%$ & $25 \%$ & $0 \%$ & 2.33 & .485 & 157 \\
\hline & & Female & $25 \%$ & $31 \%$ & $6 \%$ & 2.30 & .651 & .151 \\
\hline 1 & Sending Fmail & Male & $38 \%$ & $0 \%$ & $0 \%$ & 3.00 & .000 & 000 \\
\hline 0 & senaing Email & Female & $50 \%$ & $6 \%$ & $6 \%$ & 2.70 & .651 & .000 \\
\hline 1 & Voice Recording & Male & $25 \%$ & $13 \%$ & $0 \%$ & 2.67 & .485 & \\
\hline 1 & volce Kecoraing & Female & $31 \%$ & $31 \%$ & $0 \%$ & 2.50 & .509 & .004 \\
\hline 1 & Translate & Male & $37 \%$ & $0 \%$ & $0 \%$ & 3.00 & .000 & 000 \\
\hline 2 & Tamsiate & Female & $50 \%$ & $13 \%$ & $0 \%$ & 2.80 & .407 & .000 \\
\hline 1 & Taking Notes & Male & $31 \%$ & $6 \%$ & $0 \%$ & 2.83 & .383 & 031 \\
\hline 3 & I aking Notes & Female & $44 \%$ & $19 \%$ & $0 \%$ & 2.70 & .466 & .031 \\
\hline 1 & Mans & Male & $38 \%$ & $0 \%$ & $0 \%$ & 3.00 & .000 & \\
\hline 4 & Mraps & Female & $31 \%$ & $25 \%$ & $6 \%$ & 2.40 & .675 & .000 \\
\hline 1 & Photo and Video Alhum & Male & $31 \%$ & $6 \%$ & $0 \%$ & 2.83 & .383 & 031 \\
\hline 5 & 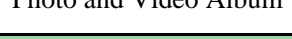 & Female & $44 \%$ & $19 \%$ & $0 \%$ & 2.70 & .466 & .001 \\
\hline 1 & Weather & Male & $25 \%$ & $6 \%$ & $6 \%$ & 2.50 & .786 & 000 \\
\hline 6 & weatner & Female & $50 \%$ & $13 \%$ & $0 \%$ & 2.80 & .407 & .000 \\
\hline 1 & Social Networking & Male & $38 \%$ & $0 \%$ & $0 \%$ & 3.00 & .000 & \\
\hline 7 & social Networking & Female & $50 \%$ & $12 \%$ & $0 \%$ & 2.80 & .407 & .000 \\
\hline 1 & J earning Purnoses & Male & $38 \%$ & $0 \%$ & $0 \%$ & 3.00 & .000 & 000 \\
\hline 8 & c- Learming t uiposes & Female & $49 \%$ & $13 \%$ & $0 \%$ & 2.80 & .407 & .000 \\
\hline
\end{tabular}

\section{B. Sample}

The sample of this study was 48 instructors, 18 males and 30 females from the College of Business Studies (CBS) in Kuwait HE. The sample involves a wide range of instructors from different fields and levels of study.

\section{Evaluation Tool}

A survey was an appropriate research tool for this study. An online questionnaire was developed in which it consisted of 2 parts. Part 1 collects demographic data; part 2 of the questionnaire investigates the use of mobile native functions and capabilities. An online questionnaire was distributed to instructors, to understand their use of mobile device native capabilities and applications.

\section{Data Analysis}

Data was collected from the online questionnaire and analyzed by using SPSS. Percentages, Mean, Standard Deviations (SD), were calculated. An independent-sample t-test was also used to assess the differences observed between means in two unrelated groups, and to determine whether there is a statistically significant difference between variables of our collected data based on instructors' gender. A significance level (sig.) of 0.05 was adopted.

\section{RESULTS AND FINDINGS}

This section presents instructors' demographic data and Instructors' use of mobile native functions and applications. 


\section{A. Instructors' Demographics}

Most of the instructors (48 instructors) are female (62\%), $(94 \%)$ of them are 25 years and older.

\section{B. Instructors' Use of Mobile Native Functions and Capabilities}

Regarding instructors' use of mobile functions and capabilities, Fig. 1 and Table I show the percentage of instructors' use of mobile native functions and applications. For example: Alarm and clock is used by $(94 \%)$; camera (88\%); Social media (88\%); WhatsApp (82\%); browsing (82\%); Albums (75\%); Map, SMS/MMS, and Sound (69\%); games $(38 \%)$; etc. In addition, the majority of the instructors (87\%) use mobiles for learning and knowledge acquisition. This is of note that instructors are using mobile phones to support teaching and learning processes. Based on instructors' responses to questions 1 to 18 , as shown in Table (1), instructors heavily use mobile native functions, and are able to use their mobile phone as a tool to gain knowledge and information online. Table I also documents instructors' familiarity with using different applications on their mobile devices. It shows that instructors are accustomed to mobile functions and applications, including camera and albums, messaging, calendar and clock, games, maps, weather, email, and social media. These findings are consistent with [4], [11], [18].

Instructors' use of mobile functions and Applications

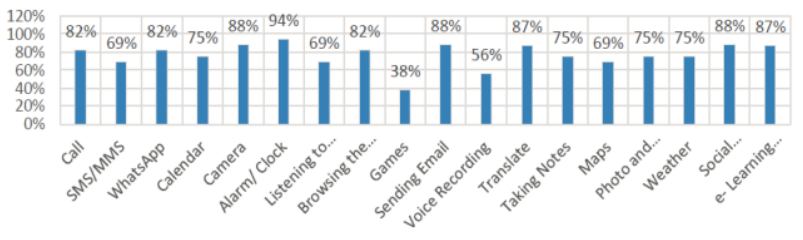

Fig. 1. Instructors' use of mobile functions and application.

T-tests, Mean, and SD were performed as shown in Table (1). Significant differences were found between male and female instructors in using mobile functions such as "Call", "SMS", "Calendar", "Camera", "Alarm/Clock", "Browsing the Web", "Sending Email", "Translate", "Taking notes", "Maps", And "Photo and Video Album", "weather", "Social Media", "m-learning". Female instructors appear to be more active than males in using mobile functions, except for Maps, male instructors use Maps more than female instructors.

\section{CONCLUSION}

A survey-based methodology was used to collect results obtained from $48 \mathrm{HE}$ instructors in the College of Business Studies (CBS) in Kuwait. This study initially aimed to investigate the extent of CBS instructors' usage and preferred functions of mobile devices and applications. Descriptive statistics, t-tests, Mean, and SD were performed. Results indicated instructors' frequent use of mobile functions and applications such as: WhatsApp, photo and video albums, and cameras to engage in content, administrative, management, and entertainment purposes. The analysis of instructors' responses revealed that the instructors welcome the use mobile phones for on and off campus activities. The aim of this study was to understand instructors' habits of the use of mobile capabilities and functions, as well as a common use of social media applications. The finding indicated instructors' frequent use of most of mobile functions and demonstrated that instructors would like to use mobile in their teaching practices. This will guide designers to identify critical success factors and help developers to effectively utilize mobile capabilities, functions, and applications in new learning strategies.

As for a future work, it is interesting to understand the relationship between instructors' age and Mobile Technology Acceptance in education (MTA). In addition, investigating instructors' technical knowledge and comparing this to mobile usage is also valuable.

\section{REFERENCES}

[1] Al-Hunaiyyan, A. Al-Sharhan, and R. Alhajri, "A new mobile learning model in the context of the smart classrooms environment: A holistic approach," International Journal of Interactive Mobile Technologies (IJIM), vol. 11, no. 3, pp. 39-56, 2017.

[2] P. Berking, M. Birtwhistle, S. Gallagher, and J. Haag, "Mobile learning survey report," Advanced Distributed Learning Initiative, 2013.

[3] A. Nassuora, "Students acceptance of mobile learning for higher education in Saudi Arabia," International Journal of Learning Management Systems, vol. 1, no. 1, pp. 1-9, 2013

[4] T. Wilen-Daugenti and A. McKee, Dual-Mode Phones: A Smart Call for Higher Education, PP. 1-12.

[5] I. Santos, O. Bocheco, and C. Habak, "A survey of student and instructor perceptions of personal mobile technology usage and policies for the classroom," Education and Information Technologies.

[6] N. Cavus, "Investigating mobile devices and LMS integration in higher education: student perspectives," Computer Science, vol. 3, pp. 1469-1474, 2011.

[7] H. S. Ebrahim, K. Ezzadeen, and A. K. Alhazmi, "Acquiring knowledge through mobile applications," International Journal of Interactive Mobile Technologies (iJIM), vol. 9, no. 3, 2014.

[8] Kuwait Telecommunications Report Q4. (2015). [Online]. Available: http://www.researchandmarkets.com/reports/3388100/kuwait-telecom munications-report-q4-2015, Kuwait

[9] A. Lenhart, "Cell phones and American adults," Pew Research Center, 2017.

[10] Synovate, "Global mobile phone survey shows the mobile is a 'remote control' for life," Synovate Survey, 2017.

[11] S. Almutairy, T. Davies, and W. Dimitriadi, "The readiness of applying m-learning among saudi arabian students at higher education," International Journal of Interactive Mobile Technologies IJIM, vol. 9 , no. 3, pp. 33-36, 2015.

[12] F. Dashti and A. Aldashti, "EFL college students' attitudes towards mobile learning," International Education Studies, vol. 8, no. 8, pp. 13-20, 2015.

[13] G. Kennedy, B. Dalgarno, S. Bennett, T. Judd, and R. Chang, "Immigrants and natives: Investigating differences between staff and students' use of technology," in Proc. the 25th annual conference of the Australasian Society for Computers in Tertiary Education (ASCILITE), Deakin University, Melbourne, Australia, 2008.

[14] G. Kennedy, S. Judd, A. Churchward, and K. Gary, "First year students' experiences with technology: Are they really digital natives?" Australasian Journal of Educational Technology, vol. 24, pp. 108-122, 2008.

[15] M. Bayless, T. Clipson, and S. Wilson, "Faculty perceptions and policies of students' use of personal technology in the classroom," Steven Austin State University, Faculty Publications, Paper 32, 2013.

[16] A. Forkosh-Baruch and H. eishar-Tal, "Proactive, preventive or indifference? Reaction modes of faculty towards use of personal mobile devices in courses," International Journal of Mobile and Blended Learning, vol. 8, no. 2, pp. 72-84, 2016.

[17] I. Santos and O. Bocheco, "Instructor perceptions of using mobile phones in teaching and learning: The case of a group of instructors in the UAE," in Proc. Global Learn 17-20 May, Penang, 2010.

[18] A. Al-Hunaiyyan, R. Alhajri, and S. Al-Sharhan, "Perceptions and challenges of mobile learning in Kuwait," Journal of King Saud University - Computer and Information Sciences, 2016. 
Ahmed A. Al-Hunaiyyan is a faculty member of the Department of Computer and Information systems at the College of Business Studies, PAAET, Kuwait. He earned his PhD. degree in the field of computer science, specializing in multimedia interface design, from Hertfordshire University, United Kingdom. As of working experience, he participated in various academic institutions, in and out of Kuwait. His research interest is Human Computer Interaction (HCI), software Usability, designing educational multimedia interfaces and social media

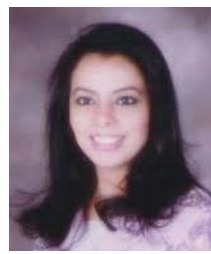

Rana Alhajri is a faculty member in the Department of Computer Science at the Higher Institute of Telecommunication and Navigation, which belongs to the Public Authority for Applied Education and Training (PAAET) in Kuwait. She earned her Ph.D degree in the field of computer science, specializing in e-learning, from Brunel University, United Kingdom. Her research interest is hypermedia, individual differences, HCI, usability, multimedia interface design in education in software use and social media. 